\title{
Left-to-Right Differences of Regional Cerebral Oxygen Saturation and Oxygen Extraction in Preterm Infants During the First Days of Life
}

\author{
PETRA M.A. LEMMERS AND FRANK VAN BEL \\ Department of Neonatology, University Medical Center/Wilhelmina Children's Hospital, 3584 EA Utrecht, The Netherlands
}

\begin{abstract}
In a prospective study, we monitored simultaneously left and right parieto-frontal-cerebral oxygen saturation $\left(\mathrm{rScO}_{2}\right)$ and cerebral fractional tissue oxygen extraction (cFTOE) using near-infrared spectroscopy in 36 very preterm neonates during the first $3 \mathrm{~d}$ of life. Simple regression analysis showed a close correlation between left and right $\mathrm{rScO}_{2}(r=0.89, p<0.01)$ and cFTOE $(r=0.88, p<0.01)$, respectively. The Bland and Altman-determined limits of agreement found overall limits of agreement of -8.5 to $+9.5 \%$ and of -0.10 to $+0.093 \%$ between left and right for $\mathrm{rScO}_{2}$ and for cFTOE, respectively. However, we found that during stable systemic oxygenation (i.e., arterial oxygen saturation $\left[\mathrm{SaO}_{2}\right.$ between 85 and 97\%]) the limits of agreement between left and right improved from -7.8 to $+8.2 \%$ and -0.088 to +0.084 for $\mathrm{rScO}_{2}$ and cFTOE, respectively (all $p<0.05$ ). We conclude that bilateral near-infrared spectroscopy-measured $\mathrm{rScO}_{2}$ and cFTOE can reveal differences up to $10 \%$ between left and right hemisphere, especially during unstable arterial saturations, which may indicate uneven cerebral oxygenation. (Pediatr Res 65: 226-230, 2009)
\end{abstract}

$\mathrm{N}$ ear-infrared spectroscopy (NIRS)-monitored cerebral oxygenation using the regional cerebral saturation $\left(\mathrm{rScO}_{2}\right)$ and the cerebral fractional tissue oxygen extraction (cFTOE), derived from $\mathrm{rScO}_{2}$ and oximetry-monitored arterial oxygen saturation $\left(\mathrm{SaO}_{2}\right)$, although not to be used as a robust quantitative variable, has been increasingly accepted to monitor substantial changes in cerebral oxygenation (1-4). NIRSmeasured $\mathrm{rScO}_{2}$ can also be used to monitor the ability of autoregulation of the cerebral arterial vascular bed when combined with simultaneous monitored arterial pressure in the (preterm) neonate (5) (De Smet D, Naulaers G, Van Huffel S, Vanderhaegen J. New measures for assessment of impaired cerebral autoregulation. Proceedings of the 35th annual ISOTT meeting, 2007, p 54). Monitoring of $\mathrm{rScO}_{2}$ and cFTOE is particularly important during the first days of life in these tiny infants because their hemodynamic condition is often unstable then with lack of cerebral autoregulation (6). Moreover, this noninvasive method is already used in the clinical setting in more mature infants as a trend monitor of cerebral oxygenation during (neonatal) cardiac surgery $(7,8)$. Although mostly used unilaterally, it has been shown that regional changes in cerebral blood flow, and by that oxygenation, may

Received July 7, 2008; accepted September 18, 2008

Correspondence: Petra M.A. Lemmers, M.D., University Medical Center/Wilhelmina Children's Hospital, Perinatal Center, Department of Neonatology, Room KE 04.123.1, PO Box 85090, 3508 AB Utrecht, The Netherlands; e-mail: p.lemmers@umcutrecht.nl occur due to regional neuronal activation (9-11). More over, Chiron et al. (12) found right brain hemisphere dominance in the young infant, which may be related to a difference in oxygenation pattern between both hemispheres of the brain. In an ongoing longitudinal study in which we monitor cerebral oxygenation and extraction in extremely preterm infants during early life using NIRS, we occasionally bilaterally monitored $\mathrm{rScO}_{2}$ using symmetrically fronto-parietally positioned transducers and detected in a minority of infants a substantial difference between left and right $\mathrm{rScO}_{2}$ values (unpublished data). A possible discrepancy between left and right hemispheric oxygenation will severely flaw the usefulness of unilaterally NIRS-monitored $\mathrm{rScO}_{2}$ and cFTOE.

Therefore, we undertook a prospective study in which we monitored cerebral oxygenation and extraction bilaterally using symmetrically positioned NIRS transducers attached to the fronto-parietal skull of very preterm neonates during the first $72 \mathrm{~h}$ of life for further elucidation of the incidence and the reasons of an asymmetrical cerebral oxygenation.

\section{PATIENTS AND METHODS}

Patient population. Thirty-six preterm infants with a gestational age (GA) less than $32 \mathrm{wk}$, who were consecutively admitted to the neonatal intensive care unit of the Wilhelmina Children's Hospital and participated in an ongoing longitudinal study in which cerebral oxygenation and extraction were monitored using NIRS for the first $72 \mathrm{~h}$ of life, were randomly included into the present study. Infants with periventricular/intraventricular hemorrhages grade 2 or higher according to the grading of Papile et al. (13) on cranial ultrasound or infants with major congenital malformations including infants with chromosomal and/or syndromatic abnormalities were excluded. Infants who subsequently developed a hemodynamically important ductus arteriosus during the recordings of NIRS-monitored $\mathrm{rScO}_{2}$ were also excluded because of its important impact on $\mathrm{rScO}_{2}$ as we earlier reported (14). Informed parental consent was obtained for all of the patients. The medical ethical committee of the University Medical Center Utrecht approved the present study.

Clinical data. Obstetrical and intrapartum data were collected from the hospital records. Neonatal data were collected prospectively. Treatment decisions were made by the attending neonatologist. All mechanical ventilated infants were sedated with morphine $10 \mu \mathrm{g} / \mathrm{kg}$ per hour. $\mathrm{SaO}_{2}$ was monitored using pulse oximetry on a limb and the arterial blood pressure by an indwelling arterial catheter (umbilical, posterior tibial, or radial artery) in all infants.

Monitoring of cerebral tissue oxygenation and oxygen extraction. NIRSdetermined regional cerebral oxygen saturation $\left(\mathrm{rScO}_{2}\right)$ was used as a reliable estimator for changes in regional cerebral oxygenation. Because absolute

\footnotetext{
Abbreviations: cFTOE, cerebral fractional tissue oxygen extraction; NIRS, near-infrared spectroscopy; $\mathbf{r S c O}_{2}$, regional cerebral oxygen saturation; $\mathbf{S a O}_{2}$, systemic arterial oxygen saturation
} 
values are provided, $\mathrm{rScO}_{2}$ is less dependent of movement artifacts and comparisons over time are possible (2). An INVOS 5100 near-infrared spectrometer (Somanetics, Troy, MI) was used. Two transducers, each containing a light-emitting diode and two distant sensors, were attached to the fronto-parietal left and right side, respectively, of the neonatal skull. $\mathrm{rScO}_{2}$ was calculated from the differential signals obtained from these 2 sensors, expressed as the venous-weighted percentage of oxygenated hemoglobin (oxygenated hemoglobin /total hemoglobin) (total hemoglobin $=$ oxygenated hemoglobin + deoxygenated hemoglobin) $(3,15)$.

To investigate the balance between oxygen delivery and oxygen consumption, the relative cFTOE can be formulated as a ratio: $\left(\mathrm{SaO}_{2}-\mathrm{rScO}_{2}\right) / \mathrm{SaO}_{2}$. An increase of cFTOE might indicate a reduced oxygen delivery to the brain with a constant oxygen consumption of the brain or higher oxygen consumption than oxygen delivery. A decrease of cFTOE suggests a decrease of oxygen extraction of the brain because of less use of oxygen or a constant oxygen consumption of the brain with an increased oxygen delivery to the brain (3).

Study design. As part of a prospective study in very preterm infants (GA $<32$ wk) patterns of $\mathrm{rScO}_{2}$ and cFTOE were recorded from left and right fronto-parietal symmetrically positioned transducers coupled to a NIRS device for at least $2 \mathrm{~h}$ or in case of unreliable recordings as long as necessary to obtain an uninterrupted recording of about $2 \mathrm{~h}$. Because our experience with this method learned us that it takes some time (5-10 min) in some infants to obtain a reliable $\mathrm{rScO}_{2}$ signal after application of the transducers, the signals used for the study were never derived from measurements during the first 10 min. Simultaneously, $\mathrm{SaO}_{2}$, arterial blood pressure, and heart rate were monitored. The simultaneously collected data were stored in a personal computer for offline analysis (Poly 5; Inspektor Research Systems, Amsterdam, The Netherlands). Recordings were performed on days 1, 2, or 3 . In 7 of the 36 infants, included in this study, another set of reliable 2-h registrations of $\mathrm{rScO}_{2}$ and cFTOE were performed in a similar setting on day 1 and again on day 3 to investigate the development of possible brain hemisphere dominance as was reported in the term neonate (12). In all infants, the arterial hemoglobin concentration was measured daily or more frequently if indicated. Arterial blood gases were determined every $4 \mathrm{~h}$ or more frequently if necessary, or less frequently after $24 \mathrm{~h}$ of life if the clinical condition was stable. Cranial ultrasound studies were performed at birth and every $24 \mathrm{~h}$ during the first $3 \mathrm{~d}$ of life (or more frequently if indicated).

Statistical analysis. Data are summarized as mean values \pm SD or as median values and ranges where appropriate. Comparisons of left versus right $\mathrm{rScO} 2$ and $\mathrm{cFTOE}$ were done based on simple linear regression analysis and the Bland-Altman analysis (16). These comparisons were done from $\mathrm{rScO}_{2}$ or cFTOE values, which were averaged over $1 \mathrm{~min}$ of a reliable recording providing us with about 120 averaged $\mathrm{rScO}_{2}$ or cFTOE values for each side per patient. Differences over postnatal age for the differences between left and right $\mathrm{rScO}_{2}$ and $\mathrm{cFTOE}$ were analyzed using analysis of variance for repeated measurements. A $p$ value of $<0.05$ was considered statistically significant. For statistical analysis, SPSS 14.0 (SPSS, Chicago, IL) was used.

\section{RESULTS}

Clinical characteristics. The clinical data of the included infants are shown in Table 1 Most infants were on continuous positive airway pressure, 9 infants were on mechanical ventilation, and 5 without any respiratory support. In all infants, $\mathrm{pCO}_{2} \mathrm{~s}$ and $\mathrm{pO}_{2} \mathrm{~s}$ were within normal limits during the monitoring of $\mathrm{rScO}_{2}$ and cFTOE (Table 1). In addition, the arterial blood pressures (Table 1) and hemoglobin concentrations were always within the normal range in all studied infants (data not shown). Median postnatal age during the recordings was $24 \mathrm{~h}$ with a range from 3 to $72 \mathrm{~h}$. The clinical characteristics of the 7 infants included in the day 1 to day 3 longitudinal study were not different from the total patient population of 36 infants.

Patterns of $\boldsymbol{r S c O} \mathrm{O}_{2}$ and $\boldsymbol{c F T O E}$. The 36 infants were monitored simultaneously on the left and right fronto-parietal part of the head for $126 \pm 34 \mathrm{~min}$ (total amount of time recordings was $4506 \mathrm{~min})$. The mean $\mathrm{rScO}_{2}$ was $68 \pm 9.2 \%$ and $67 \pm$ $9.6 \%$ for the left and right side, respectively. Mean cFTOE was $0.28 \pm 0.095$ and $0.28 \pm 0.099$ for the left and right side,
Table 1. Important clinical characteristics

\begin{tabular}{|c|c|}
\hline Clinical data & $(n=36)$ \\
\hline Gestational age (wk: median [range]) & $29.7[25.8-31.6]$ \\
\hline Birth weight (grams: median [range]) & $1225[630-2000]$ \\
\hline $\operatorname{Sex}(m / f)$ & $14 / 22$ \\
\hline \multicolumn{2}{|l|}{ Apgar score (median [range]) } \\
\hline $1^{\prime}$ & $7[1-9]$ \\
\hline $5^{\prime}$ & $8[6-10]$ \\
\hline Postnatal age (h: median [range]) & $24[3-72]$ \\
\hline $\begin{array}{l}\text { Mean arterial blood pressure } \\
\quad(\mathrm{mm} \mathrm{Hg})(\text { Mean }( \pm \mathrm{SD}))\end{array}$ & $39( \pm 6.1)$ \\
\hline $\mathrm{pCO}_{2}(\mathrm{~mm} \mathrm{Hg})($ mean $( \pm \mathrm{SD}))$ & $44( \pm 7)$ \\
\hline $\mathrm{pO}_{2}(\mathrm{~mm} \mathrm{Hg})($ mean $( \pm \mathrm{SD}))$ & $57( \pm 14)$ \\
\hline \multicolumn{2}{|l|}{ Respiratory support $(n[\%])$} \\
\hline No support & $5(13)$ \\
\hline CPAP & $22(61)$ \\
\hline SIMV & $7(19)$ \\
\hline HFOV & $2(5)$ \\
\hline
\end{tabular}

CPAP, continuous positive airway pressure; SIMV, synchronized intermittent mandatory ventilation; HFOV, high-frequency oscillatory ventilation.

respectively. There was a close correlation between left and right 1 min averaged values of $\mathrm{rScO}_{2}$ and cFTOE $(r=0.89$, $p<0.01$ and $r=0.88, p<0.01$, respectively) as shown in Figure 1a and b. Differences between left and right for $\mathrm{rScO}_{2}$ and for cFTOE had a normal distribution (mean \pm SD: $0.5 \pm$ $4.5 \%$ and $0.005 \pm 0.05$ ). Most periods with a substantial difference between left and right $\mathrm{rScO}_{2}$ and cFTOE (i.e., $>1$ $\mathrm{SD}$, being $4.5 \%$ and 0.05 for $\mathrm{ScO}_{2}$ and cFTOE, respectively) were short-lived and predominantly related with an unstable $\mathrm{SaO}_{2}$ pattern, such as hypoxemia $\left(\mathrm{SaO}_{2}<85 \%\right)$; hyperoxemia $\left(\mathrm{SaO}_{2} \geq 98 \%\right)$ or a combination of hypoxemia and hyperoxemia. See for a representative $\mathrm{rScO}_{2}$ pattern during stable and unstable $\mathrm{SaO}_{2}$ s Figure 2a and b, respectively.

Figure $3 a$ and $b$ shows the Bland-Altman plot with the limits of agreement between left- and right-determined $\mathrm{rScO}_{2}$ and cFTOE during both unstable and stable $\mathrm{SaO}_{2}$ values. When all data were used, these limits were -8.5 to $+9.5 \%$ and -0.10 to $+0.093 \%$, respectively. Important to state and as can be extracted from the regression- and Bland-Altman plots (Figs. 1 and 3, respectively), left and right lower/higher $\mathrm{rScO}_{2}$ and cFTOE-values were equally divided over the right and left fronto-parietal measured values. Figure $3 c$ and $d$ shows the Bland-Altman plot with the limits of agreement between left-
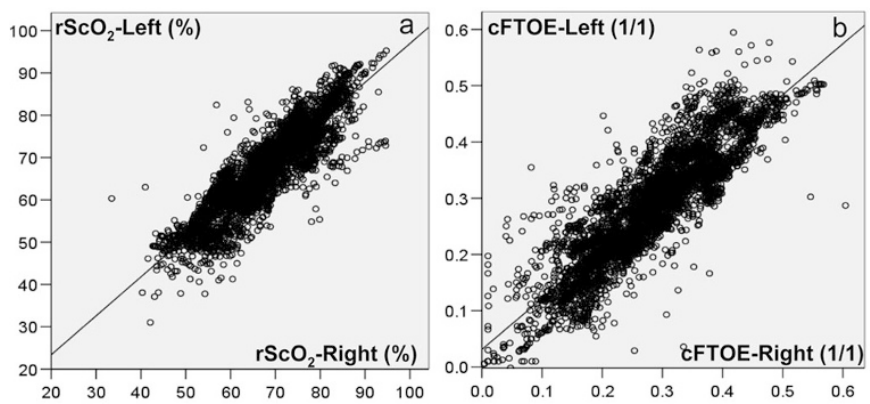

Figure 1. Simple regression plot of the near-infrared spectroscopy (NIRS)monitored regional cerebral oxygen saturation $\left(\mathrm{rScO}_{2}\right)$ as a function of left and right $\mathrm{rScO}_{2}(r=0.89, p<0.01)(a)$, the calculated cerebral fractional tissue oxygen extraction (cFTOE) as a function of left and right FTOE $(r=0.88, p<0.01)(b)$. 

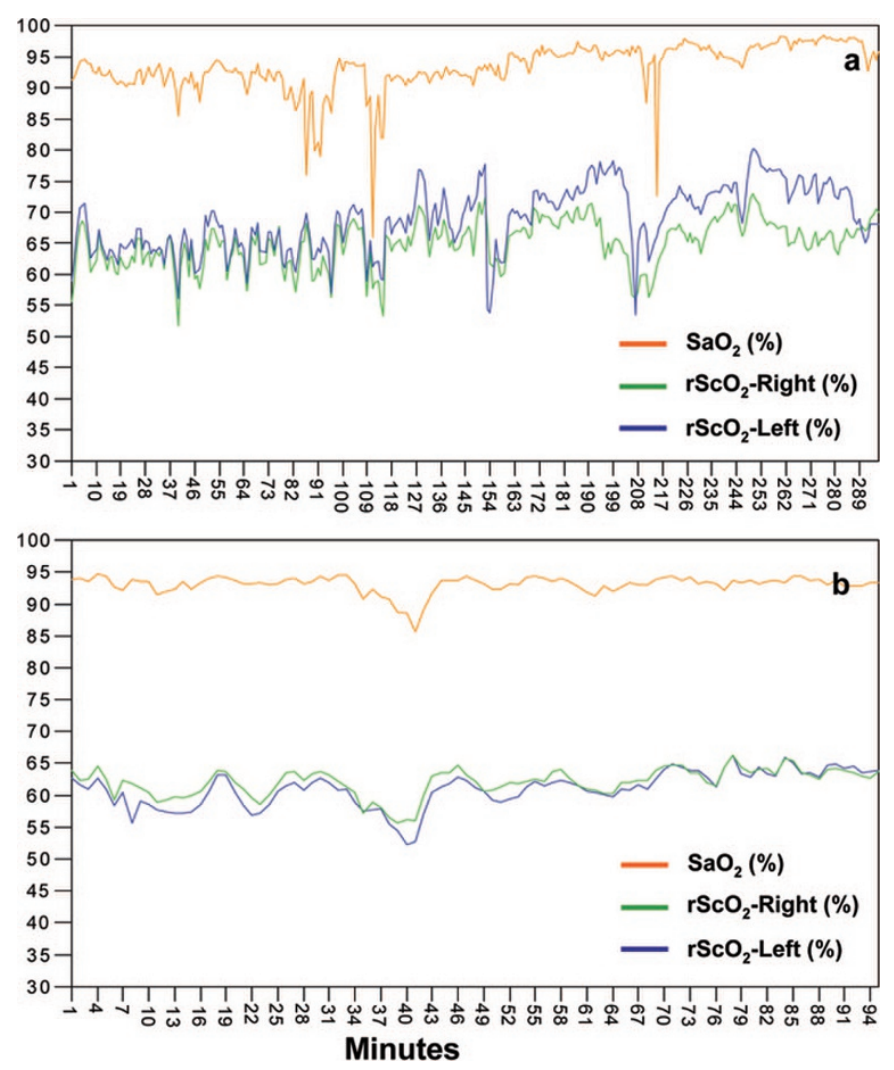

Figure 2. (a) Representative pattern of $2 \mathrm{~h}$ of left (blue line) and of right (green line) regional cerebral oxygen saturation $\left(\mathrm{rScO}_{2}\right)$ during all systemic arterial oxygen saturations $\left(\mathrm{SaO}_{2}\right.$; orange line); $(b)$ left and right $\mathrm{rScO}_{2}$ patterns during stable $\mathrm{SaO}_{2}$. Note differences in left and right $\mathrm{rScO}_{2}$ values during substantial decreases in $\mathrm{SaO}_{2}$.

and right-determined $\mathrm{rScO}_{2}$ and cFTOE after extraction of 22 hypoxemic and/or hyperoxemic periods. Values now were -7.8 to +8.2 and -0.088 to +0.084 , respectively, indicating an improvement of the limits of agreement during stable systemic $\mathrm{SaO}_{2}(p<0.05)$. The longitudinal 2-h patterns of $\mathrm{rScO}_{2}$ and cFTOE at day 1 and day 3 , extracted from tracings during stable $\mathrm{SaO}_{2}$ values which were always within normal limits (i.e., $85-95 \%$ ) showed a not significant difference with higher $\mathrm{rScO}_{2}$ and cFTOE values at day 3 compared with day 1 of life. On day 1, no left-to-right asymmetry was found (Fig. 4).

There was no correlation between $\mathrm{rScO}_{2}$ and mean arterial blood pressure or cFTOE and mean arterial blood pressure ( $r=0.05$ and $r=0.04$, respectively).

\section{DISCUSSION}

The present study shows a symmetrical cerebral oxygenation of the immature brain during stable arterial oxygen saturation within expected limits (2) during the first $3 \mathrm{~d}$ in the very preterm infant, as indicated by the similar values of NIRS-monitored left and right fronto-parietal $\mathrm{rScO}_{2}$, although our small longitudinal study is showing a slight tendency for higher $\mathrm{rScO}_{2}$ values at the right fronto-parietal position at day 3. This pattern changes during an unstable arterial oxygenation pattern with substantial drops of $\mathrm{SaO}_{2}$ with or without subsequent hyperoxemia, when extra oxygen was added for a quick recovery of arterial saturation. Then differences between left and right $\mathrm{SaO}_{2}$ values up to more than $10 \%$ could be detected. Mostly a symmetrical cerebral oxygenation pattern reappeared when arterial saturation remained stable and within normal limits for another 10-15 min.

These results are important when one relies on NIRSdetermined cerebral oxygenation using $\mathrm{rScO}_{2}$. We assume that the difference between left and right $\mathrm{rScO}_{2}$ values during these unstable arterial saturations was not an artifact but indeed indicate an uneven cerebral oxygenation in those regions of the brain from where the $\mathrm{rScO}_{2}$ is derived. We can only speculate what the reasons are for this apparent uneven oxygenation of the brain, in particular during unstable arterial saturations. Despite the findings of Chiron et al. (12) who reported a functional dominance of the right brain hemisphere in the young infant and making it conceivable that during recovery from an arterial saturation drop the right hemispheric oxygenation should recover more quickly than the oxygenation of the left hemisphere, we could not confirm this. As clearly indicated by the Bland-Altman plots (Fig. 3), no preference for the right or left measurement side was detected
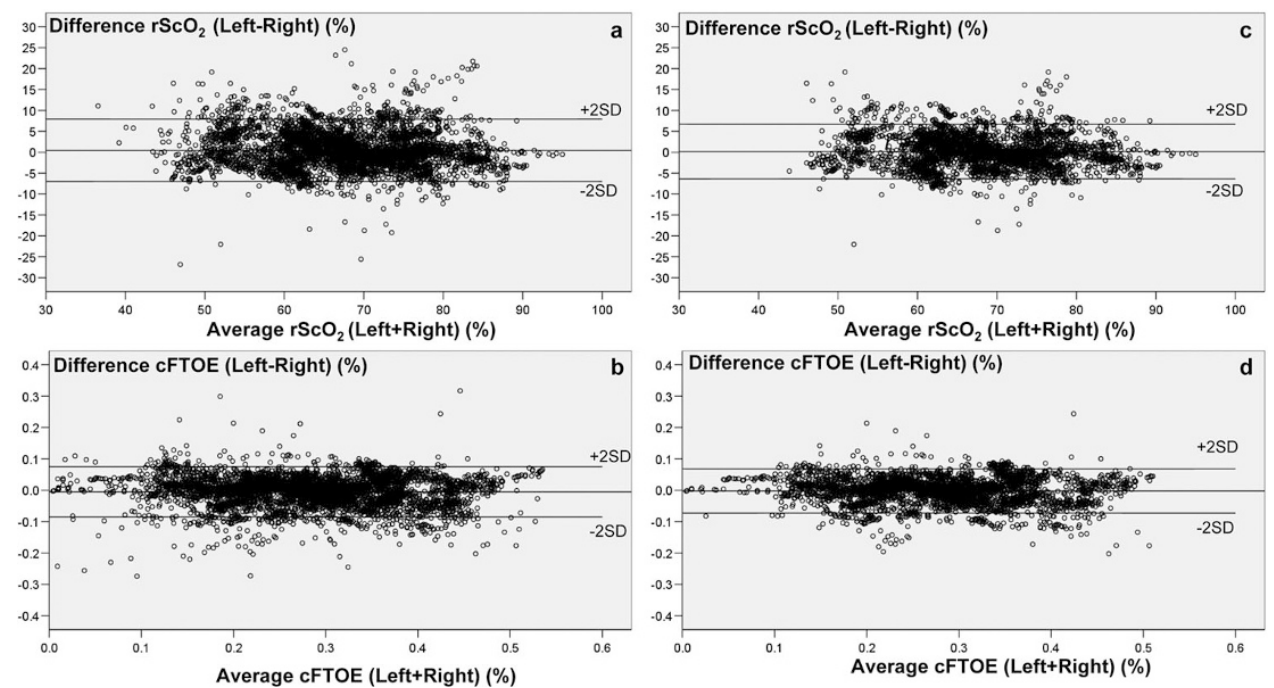

Figure 3. Limits of agreement according to Bland and Altman (16) in 36 infants between left and right near-infrared spectroscopy (NIRS)-monitored regional cerebral oxygen saturation $\left(\mathrm{rScO}_{2}\right)(a)$ and of NIRS-monitored cerebral fractional tissue oxygen extraction (cFTOE) (b) obtained when all simultaneously monitored systemic oxygen saturations $\left(\mathrm{SaO}_{2} \mathrm{~s}\right)$ were included; $(c)$ and $(d)$ obtained when only $\mathrm{rScO}_{2}$ and cFTOE determinations were included during stable $\mathrm{SaO}_{2} \mathrm{~S}$ within the normal range $(p<0.05)$. 

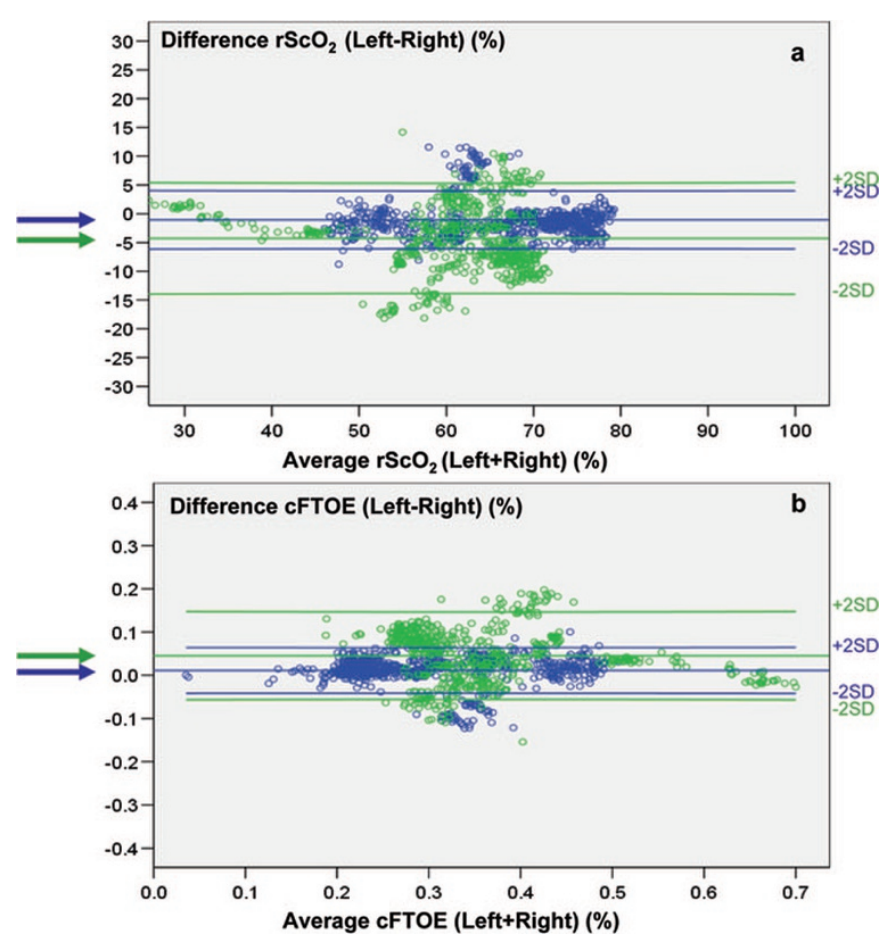

Figure 4. Limits of agreement according to Bland and Altman (16) between left and right near-infrared spectroscopy (NIRS)-monitored regional cerebral oxygen saturation $\left(\mathrm{rScO}_{2}\right)(a)$ and cerebral fractional tissue oxygen extraction (cFTOE) (b) monitored in 7 very preterm infants on day 1 (blue dots and lines) and again on day 3 (green dots and lines) of life. Note the shift of the mean left-to-right difference from day 1 to day 3 (arrows) from -0.5 to -4.2 indicating that slightly higher $\mathrm{rScO}_{2}$ values are detected by the transducer attached to the right fronto-parietal position. The same is true for the right detected cFTOE (NS).

here. However, our investigated population was very preterm (GA $<32 \mathrm{wk}$ ), making it probable that hemispheric dominance was not developed yet: at least no such studies are published with respect to very preterm infants by our best knowledge concerning this issue. Although it remains highly speculative, the tendency for higher right-sided $\mathrm{rScO}_{2}$ values on day 3 might be an indication for development of hemispheric dominance (Fig. 4). However, additional studies in populations of different GAs and postnatal ages are necessary to prove this hypothesis. There are not many studies reporting on differences between left and right NIRS-monitored $\mathrm{rScO}_{2}$ values. Asymmetries in cerebral oxygenation have been predominantly attributed to intracranial flow restrictions in cerebral arteries, such as the carotid arteries, because of intracranial processes such as infarctions or hemangioma's and interference from an infrared-emitting device or ambient light $(12,17)$. We were fairly sure that these complications or technical artifacts (in case of ambient light, the monitor used in our neonatal intensive care unit should have alarmed for excessive light) did not cause the reported left-to-right differences in $\mathrm{rScO}_{2}$ in our study during unstable $\mathrm{SaO}_{2}$ values. Also during cardiac surgery, asymmetry of NIRS-monitored cerebral oxygenation $\left(\mathrm{rScO}_{2}\right)$ have been reported, mostly in relation with complications during aortic or venous canulation and patients on cardiopulmonary bypass (18-20). Theoretically, the only cardiac complication in our population of very pre- term infants, which may be a realistic possibility to be a reason for uneven cerebral oxygenation, is a ductal steal phenomenon $(12,17)$ induced by a hemodynamically significant ductus arteriosus, because the duct is situated distally from the right subclavian artery but proximal of the left carotid artery. However, the fact that lower $\mathrm{rScO}_{2}$ values were equally divided over the right and left fronto-parietal measured values and the fact that the difference of $\mathrm{rScO}_{2}$ was only temporarily asymmetrical during lower arterial saturation values makes this suggestion not very probable. Moreover, none of the infants had signs of a hemodynamically important duct. Finally, the possibility for anomalies of the circle of Willis, a not infrequent occurring anomaly in humans (21), is less probable given the temporary character of the differences in left and right $\mathrm{rScO}_{2} \mathrm{~S}$.

In our studied population, and another study in term newborns and infants (7), the detected differences between left and right $\mathrm{rScO}_{2} \mathrm{~S}$ were transient and not more than $10 \%$. This may justify unilateral monitoring of cerebral oxygenation, albeit only true for the first days of life. On the other hand, with the now available very sophisticated and small NIRS transducers which make fixation to the skull very easy, even in the smallest preterm baby, one can argue that bilateral monitoring should be advisable especially when NIRS monitoring will be performed longer than the first days of life or in the more mature baby.

Limitations of our study, however, should also be mentioned here. First, in our study, transducers were placed over the fronto-parietal skull. However, the temporal-occipital part of the brain has a very high perfusion and metabolism (12), even in the preterm infant. We did not monitor cerebral oxygenation in this part of the brain in which the most lateralized functions such as handedness and language will develop later in life, so we cannot exclude differences between left and right $\mathrm{rScO}_{2}$ in this region of the skull. Although we were dealing with very immature babies here, in whom these considerations may be much too "premature," we suggest further research concerning this particular issue. Second, we did not specify the position of the head, which may influence the venous-arterial ratio of the $\mathrm{rScO}_{2}(22,23)$. However, we suggest that this issue had not a substantial impact on the $\mathrm{rScO}_{2}$ measured, because in most cases differences between simultaneous left-right measured $\mathrm{rScO}_{2}$ were quite small. Third, we are aware that despite arterial $\mathrm{pCO}_{2}$ and $\mathrm{pO}_{2}$ values and blood pressures were within physiologic limits (see also Table 1) these parameters may have had an impact on the study results. For $\mathrm{pCO}_{2}$ and $\mathrm{pO}_{2}$ it is not possible to make a reliable statement on base of the study because these parameters were not continuously monitored.

With respect to blood pressure, the lack of correlation between left-right differences of $\mathrm{rScO}_{2}$ and mean arterial blood pressure $(r=0.05)$ and FTOE and mean arterial blood pressure $(r=0.04)$ makes an important role of blood pressure in infants in the present study less probable. Finally, it is important to reiterate that the monitored $\mathrm{rScO}_{2}$ in the present study is specific for the INVOS 5100 device.

In conclusion, during stable and normal arterial saturations, differences between left and right NIRS-monitored $\mathrm{rScO}_{2} \mathrm{~s}$ and cFTOEs were minor and did rarely exceed $7 \%$, even at day 3 
of life when a slight hemisphere dominance may be the case. We therefore suggest that unilateral NIRS monitoring can serve as a trend monitoring in the individual patient to detect important changes in $\mathrm{rScO}_{2}$ and cFTOE in most situations and provide us with important clinical information. Therefore, during substantial drops of $\mathrm{SaO}_{2}$, transient differences occurred up to over $10 \%$ between left and right $\mathrm{rScO}_{2}$ values. These differences make that bilateral NIRS monitoring of cerebral oxygenation, which is easy, noninvasive, and reliable nowadays, because of the very sophisticated transducers which are easy to attach to the skull, may be advisable for further improvement of assessment of regional cerebral oxygenation of the immature brain. Finally, we want to suggest, although beyond the scope of the present study, that further studies are recommended to determine whether this technique can help us to identify unilateral pathology.

\section{REFERENCES}

1. McCormick PW, Stewart M, Goetting MG, Dujovny M, Lewis G, Ausman JI 1991 Noninvasive cerebral optical spectroscopy for monitoring cerebral oxygen delivery and hemodynamics. Crit Care Med 19:89-97

2. van Bel F, Lemmers P, Naulaers G 2008 Monitoring neonatal regional cerebral oxygen saturation in clinical practice: value and pitfalls. Neonatology 94:237-244

3. Naulaers G, Meyns B, Miserez M, Leunens V, Van Huffel S, Casaer P, Weindling M, Devlieger H 2007 Use of tissue oxygenation index and fractional tissue oxygen extraction as non-invasive parameters for cerebral oxygenation. A validation study in piglets. Neonatology 92:120-126

4. Sorensen LC, Greisen G 2006 Precision of measurement of cerebral tissue oxygenation index using near-infrared spectroscopy in preterm neonates. J Biomed Opt 11:054005

5. Brady KM, Lee JK, Kibler KK, Smielewski P, Czosnyka M, Easley RB, Koehler RC, Shaffner DH 2007 Continuous time-domain analysis of cerebrovascular autoregulation using near-infrared spectroscopy. Stroke 38:2818-2825

6. Soul JS, Hammer PE, Tsuji M, Saul JP, Bassan H, Limperopoulos C, Disalvo DN, Moore M, Akins P, Ringer S, Volpe JJ, Trachtenberg F, du Plessis AJ 2007
Fluctuating pressure-passivity is common in the cerebral circulation of sick premature infants. Pediatr Res 61:467-473

7. Andropoulos DB, Diaz LK, Fraser CD Jr, McKenzie ED, Stayer SA 2004 Is bilateral monitoring of cerebral oxygen saturation necessary during neonatal aortic arch reconstruction? Anesth Analg 98:1267-1272

8. Kussman BD, Wypij D, DiNardo JA, Newburger J, Jonas RA, Bartlett J, McGrath E, Laussen PC 2005 An evaluation of bilateral monitoring of cerebral oxygen saturation during pediatric cardiac surgery. Anesth Analg 101:1294-1300

9. Austin EH 3rd, Edmonds HL Jr, Auden SM, Seremet V, Niznik G, Sehic A, Sowell MK, Cheppo CD, Corlett KM 1997 Benefit of neurophysiologic monitoring for pediatric cardiac surgery. J Thorac Cardiovasc Surg 114:707-717

10. Kamba M, Sung YW, Ogawa S 2007 Alteration of blood oxygenation level-dependent signaling by local circulatory condition. J Magn Reson Imaging 26:1506-1513

11. Bartocci M, Winberg J, Papendieck G, Mustica T, Serra G, Lagercrantz H 2001 Cerebral hemodynamic response to unpleasant odors in the preterm newborn measured by near-infrared spectroscopy. Pediatr Res 50:324-330

12. Chiron C, Jambaque I, Nabbout R, Lounes R, Syrota A, Dulac O 1997 The right brain hemisphere is dominant in human infants. Brain 120:1057-1065

13. Papile LA, Munsick-Bruno G, Schaefer A 1983 Relationship of cerebral intraventricular hemorrhage and early childhood neurologic handicaps. J Pediatr 103:273-277

14. Lemmers PM, Toet MC, van Bel F 2008 Impact of patent ductus arteriosus and subsequent therapy with indomethacin on cerebral oxygenation in preterm infants. Pediatrics 121:142-147

15. Edwards AD, Wyatt JS, Richardson C, Delpy DT, Cope M, Reynolds EO 1988 Cotside measurement of cerebral blood flow in ill newborn infants by near infrared spectroscopy. Lancet 2:770-771

16. Bland JM, Altman DG 1986 Statistical methods for assessing agreement between two methods of clinical measurement. Lancet 1:307-310

17. Edmonds HL Jr, Ganzel BL, Austin EH 3rd 2004 Cerebral oximetry for cardiac and vascular surgery. Semin Cardiothorac Vasc Anesth 8:147-166

18. Bar-Yosef S, Sanders EG, Grocott HP 2003 Asymmetric cerebral near-infrared oximetric measurements during cardiac surgery. J Cardiothorac Vasc Anesth 17:773-774

19. Janelle GM, Mnookin S, Gravenstein N, Martin TD, Urdaneta F 2002 Unilateral cerebral oxygen desaturation during emergent repair of a DeBakey type 1 aortic dissection: potential aversion of a major catastrophe. Anesthesiology 96:1263-1265

20. Sakamoto T, Duebener LF, Laussen PC, Jonas RA 2004 Cerebral ischemia caused by obstructed superior vena cava cannula is detected by near-infrared spectroscopy. J Cardiothorac Vasc Anesth 18:293-303

21. Alpers BJ, Berry RG, Paddison RM 1959 Anatomical studies of the circle of Willis in normal brain. AMA Arch Neurol Psychiatry 81:409-418

22. Pellicer A, Gaya F, Madero R, Quero J, Cabanas F 2002 Noninvasive continuous monitoring of the effects of head position on brain hemodynamics in ventilated infants. Pediatrics 109:434-440

23. Ichihashi K, Iino M, Eguchi Y, Uchida A, Honma Y, Momoi M 2002 Effect of head position to the cerebral arterial flow in neonates. Early Hum Dev 69:35-46 